\title{
Performance Evaluation of an Innovative Self-Compensating Gated Pipe System for Furrow Irrigation: Preliminary Results
}

\author{
Nicola Lamaddalena ${ }^{1 *}$, Roula Khadra ${ }^{2}$, Giovanna Dragonetti ${ }^{2}$, Abdelouahid Fouial ${ }^{2}$, Ahmed Ali Rashed ${ }^{3}$, Ahmed \\ Ayoub $^{1,4}$, Bruno Molle $^{5}$ and Catherine Gibert ${ }^{6}$
}

${ }^{1}$ CIHEAM-Mediterranean Agronomic Institute of Bari, Italy

${ }^{2}$ Department of Land and Water Resources Management, CIHEAM-Mediterranean Agronomic Institute of Bari, Italy

${ }^{3}$ Water Management and Irrigation Systems Research Institute, National Water Research Center, Egypt

${ }^{4}$ Department of Agricultural and Environmental Science, Bari University, Italy

${ }^{5}$ IRSTEA Irrigation Sciences and Techniques Research and Experimentation Platform, France

${ }^{6}$ Rolland Arroseurs /Sprinklers, France

Submission: May 14, 2021; Published: May 20, 2021

*Corresponding author: Nicola Lamaddalena, CIHEAM-Mediterranean Agronomic Institute of Bari, Via Ceglie 9, 70010 Valenzano, Italy

\section{Abstract}

An innovative self-compensating gated pipe system equipped with calibrated nozzles was developed in the framework of the EU project MADFORWATER no. (H2020-E.3.5.4 GA ID: 688320) to improve the performance of furrow irrigation method. The experiment was conducted in CIHEAM-Bari experimental field (Italy) on bare soil. The following performance indicators were assessed: duration of the irrigation event (IT), application efficiency (AE), distribution uniformity (DU), in addition to the volume of drainage water accumulated downstream and compared with traditional furrow irrigation. Preliminary results showed that IT decreased by one third (from 45 minutes to 30 minutes), AE and DU increased by $17 \%$ and $20 \%$ respectively. In addition, the volume of drainage water decreased by around $50 \%$, which may positively impact the environment, especially in those countries such as Egypt where, during peak periods, drainage water is reused for irrigation. This new technique provides a cost-effective alternative to traditional surface irrigation methods with no requirement for additional energy consumption requirements for pumping drainage water into the upstream irrigation canals. Additional field tests will be carried out in different environmental contexts and on cropped areas to confirm the above reported preliminary results.

Keywords: Innovative calibrated nozzle; Gated pipe; Water management; System performance

\section{Introduction}

Distinguished with low capital cost, low energy consumption, and traditional/cultural legacy, surface irrigation is the dominant irrigation technique, representing $86 \%$ of the fully controlled irrigated areas especially in developing countries [1].This irrigation technique is widely used because it does not require modern technology and can be adapted to local traditional knowledge. However, if not well managed, surface irrigation can have very low Water Use Efficiency (WUE) and Water Productivity. Nowadays, the increase of water shortages, which is caused by climate change, population growth and economic development, is putting unprecedented pressure on the finite renewable water resources especially in arid regions. For this reason, many governments opted to carry on ambitious modernization programs for the irrigation sector, as it is a major user of water resources. The main target of those programs is to convert from surface to pressurized systems, with support of subsidies up to $100 \%$ of the field system costs. In their important report, [2] discussed irrigation improvements by reviewing publications and addressing 150 experts from 13 different countries around the world, trying to answer one question "does improved irrigation technology save water?". The report concluded that better accounting and physical controlling for water resources is needed before answering the question. Results of on-farm scale one-dimensional comparative assessments are misleading when addressing water savings on a 


\section{Civil Engineering Research Journal}

regional scale, as most of the time the water saved is reallocated to other plots in the farm. In terms of energy, $23-48 \%$ of the energy used directly for crop production is for on-farm water pumping [3], without considering the energy mobilized to manufacture the equipment. Meaning that at least primary energy must be embedded when discussing irrigation efficiency. Although the accepted fact of low WUE of surface irrigation systems, they are characterized by low energy consumption and low equipment intensity which explains their popularity. In the last decades, intensive technology transformations in modernization programs aiming to save water resulted in a significant increment in energy consumption in several areas around the world. Southern Spain is a good example, where modernization increased energy consumption from $2136 \mathrm{GWh}$ in 1996 to 3647 GWh in 2011, an increment of $70 \%$ [4]. Several other Mediterranean countries have ongoing modernization programs under similar criteria as well.

It is quite clear that the irrigation modernization projects had to put into consideration the technical enhancement of traditional on-farm irrigation systems without transformation to technologies with intensive energy consumption. Such an alternative could be qualified by evaluating the performance of innovative surface irrigation systems. The approach of the evaluation had to account for water-energy relations and had to consider clearer efficiency definition. Therefore, the potential significance of addressing modernization of surface irrigation systems without increasing energy consumption is crucial. Surface irrigation includes a broad class of irrigation methods in which water is distributed over the field by gravity. Flow is introduced at a high point or along the high edge of the field and allowed to cover the field by overland flow. The rate of the coverage depends on the difference between the discharge and the accumulating infiltration, and secondary factors including field slope and roughness [5]. In the last decades, several technical and managerial enhancements were developed to improve the performance of furrow irrigation. One of these enhancements includes the use of gated pipes technique to attain higher distribution uniformity in shorter irrigation time. This technique is based on using, instead of open ditches, low pressure (under 1 bar) distribution pipes made of plastic or aluminum and with diameters ranging between 100 and $250 \mathrm{~mm}$ [6]. In Egypt, the situation is not so far from the worldwide picture, $85 \%$ of the irrigated land is surface irrigated with low on farm irrigation efficiency. The old delta of Egypt is distinguished with fragmented small agriculture land tenures. However, due to the distinguished topography of the Nile Valley, the high reusability of the supplied water increases the global irrigation efficiency in quantitative terms but what about the water quality? [7] states that a significant number of diseases are water borne because of this multi cycle management approach, polluted water also affects the ecosystem's balance, the soil quality, and seeps into the aquifers. They concluded that Egypt needs to set up strong standards for water quality and control the drainage nutrients, pesticides and waste found in the water

The performance of furrow irrigation under gated pipes is discussed in several research publications. By far, most of the published researches follow mainly two approaches: i) comparing gated pipes to conventional irrigation systems in terms of yield, WUE (on-farm scale) and advance time of irrigation, or ii) modifying the gated pipe systems either by technical improvement, e.g. self-compensating outlets, or by exploiting the manageability of these systems through better practices, e.g. alternate irrigation and surge irrigation. The following is a review of the latest comparative assessments and their used indicators for gated pipe systems in the last three decades. [8] compared cotton production under furrow and drip irrigation in clay soil for four seasons. Although the drip WUE was higher by 16\%, it was concluded that water productivity $\left(\mathrm{kg} / \mathrm{m}^{3}\right.$ applied water) of furrow irrigation in vertisols is relatively high and could achieve similar efficiency to drip irrigation by

a) reducing conveyance and distribution losses between pump and field,

b) reducing runoff losses from the field,

c) recirculating runoff water, and

d) reducing waterlogging.

[9] also focused on yield parameters as comparative indicators between furrow gated pipes, drip and subsurface drip systems. In terms of yield, both furrows and subsurface drip systems provided similar results. However, the applied water for the two drip systems ranged between $43-74 \%$ of that given to the furrow system. In addition, the variability of the plant mass was less in the drip systems indicating better distribution uniformity. The study concluded that conversion from furrow irrigation to drip irrigation does not increase the revenue, expecting that savings from reduced water costs are insufficient to compensate the capital and energy costs of the drip irrigation systems. [7] found that WUE can be improved by 12$29 \%$ when using well designed gated pipes instead of traditional surface irrigation for the cultivation of cotton and wheat, under Egyptian conditions. Similar results were achieved considering yield and water application for the cultivation of five different varieties of corn under gated and traditional irrigation systems [10-12] compared yields of cotton, wheat, corn, and rice under gated pipes and flooding irrigation and indicated that the yields of these crops were higher under gated pipes by 61.1, 65.2, 116 and $53.6 \%$, respectively, while significant water savings were achieved (29.64, 29.9, 14.5 and $19.7 \%$, respectively). [13] found that using gated pipes could raise sugar cane productivity by 11.8 - $16 \%$ while saving $32.3-35.6 \%$ of water, decreasing the irrigation time by $37-38 \%$, and rising the total irrigation efficiency to $75 \%$ compared to conventional systems (flood irrigation and planting in furrow) for El-Minia, Luxor and Aswan regions. 


\section{Civil Engineering Research Journal}

Under maize cultivation, [14] compared practices rather than systems. Water distribution uniformity, irrigation advance, WUE and yield production were used to compare three different gated pipe practices: alternate furrow irrigation, fixed furrow irrigation, and conventional furrow irrigation. The alternate furrow irrigation (which means alternating between each neighboring furrow in each irrigation event) showed significant water savings (up to 50\%) with no significant reduction in yield. On the other hand, several studies modified the gated pipe systems to improve its performance. The modified gated pipe system, or self-compensating gated pipe (SCGO), is usually equipped with an internal piece of flexible diaphragm inside each gate. The shape of this diaphragm changes to maintain constant pressure along the pipe $[15,16]$ carried out an experiment using a $150 \mathrm{~mm}$ gated pipe to determine the best opening areas for normal rectangular sliding gates to achieve the maximum distribution uniformity, by compensating the variation in pressure head. [17] developed a 50 mm self-compensating circular outlet with an average discharge of $29 \mathrm{l} / \mathrm{min}\left(0.54^{*} 10^{-3} \mathrm{~m}^{3} / \mathrm{sec}\right)$, obtained at a low-pressure range of 2 - $9 \mathrm{kPa}$ and with coefficients of variation less than $0.9 \%$. This modified system was compared to the traditional gated pipe system using the uniformity coefficient and water productivity. The Christiansen coefficient of uniformity was improved from 82.7 to $96.3 \%$. In addition, the water productivity of the modified gated pipe irrigation was $3,4.7$ and $5.3 \mathrm{~kg} / \mathrm{m}^{3}$ by providing $100 \%$, $75 \%$ and $50 \%$ of the crop evapotranspiration $\left(\mathrm{ET}_{\mathrm{C}}\right.$ ), respectively, while the water productivity for traditional gated pipe irrigation system was 2, 2.5 and $3.6 \mathrm{~kg} / \mathrm{m}^{3}$, for the same ETc, respectively [18]. Used SALTMED model to predict potato yield, soil moisture distribution, dry matter, and water productivity under modified gated pipes to determine the optimum gate spacing for potato cultivation between $0.7,1$ and $1.5 \mathrm{~m}$. The model and field data showed that $1.5 \mathrm{~m}$ spacing is the optimum selection in terms of yield and cost. It was concluded that the model can be used for design purposes to identify the optimum and economic gate spacing. From all the aforementioned researches, one could conclude that:

a. to assess the system performance, most of the comparative assessments depend on yield (kg/ha), seasonal water application $\left(\mathrm{m}^{3} / \mathrm{ha}\right)$ and/or water productivity in $\left(\mathrm{kg} / \mathrm{m}^{3}\right)$;

b. Energy consumption is not embedded in the performance concept, although energy could account for more than $30 \%$ of management, and operation and maintenance costs [19];

c. Each indicator is presented separately usually as a percentage of business-as-usual scenario;

d. regardless of the network size, no optimization or technical interpretation was given for selecting the pipe diameters for gated pipe systems.

Within the framework of the EU project MADFORWATER no. (H2020-E.3.5.4 GA ID: 688320) one of the objectives of the project was to substitute the existed traditional furrow irrigation system with another alternative. An innovative self-compensating outlet was developed to maximize the distribution uniformity along the gated pipe system. The objective of this work is to evaluate this innovative outlet in the field by comparing it to a traditional furrow irrigation system in terms of distribution uniformity and application efficiency.

\section{Materials and Methods}

\section{Innovative self-compensating gates}

Any opening gate follows the relation:

$$
Q=C_{d} A \sqrt{2 g h}(1)
$$

Where $Q$ is the outlet discharge in $\left(\mathrm{L}^{3} / \mathrm{T}\right), C_{d}$ is the coefficient of discharge, $A$ is the Orifice area, $g$ is the gravitational acceleration in $\left(\mathrm{L} / \mathrm{T}^{2}\right)$, and $h$ is the water head in (L). Under the same orifice diameter and assuming identical orifices, the discharge is function of the operating pressure head, which could vary along the pipe according to the length of the pipe, pipe diameter, spaces between the gates (number of gates), pipe material, slope, and upstream operating pressure. The pressure reduction causes the variation of the discharge along the gated pipe and impacts the overall distribution uniformity. The proposed selfcompensating gated outlets contains an elastic membrane that extends with higher pressures consequently restricting the outlet opening and reducing the resulted discharge. As the operating pressures at along the outlets change with a number of factors: pipe length, material, upstream pressure, upstream discharge and slope, the discharges changes accordingly and maintains a constant discharge along the gated pipe (Figure 1a), developed by ROLLAND-Irrigation (France) in the framework of the European Union MADFORWATER project (MADFORWATER, 2020). The characteristic curve (discharge vs pressure) for this type of outlets was provided by the manufacturer and is illustrated in (Figure 1b). These outlets maintain a discharge between 0.8-1 l/s in a pressure range from 0.2 to 0.5 bars $(2-5 \mathrm{~m})$.

\section{Case study}

The study was conducted in the CIHEAM-BARI experimental field in Valenzano, Italy. The field layout is $20 \mathrm{~m}$ wide and $50 \mathrm{~m}$ long with a land leveled $0.3 \%$ longitudinal slope. It encompasses 18 furrows out of which, half of them were used to test the performance of the self-compensating gated pipes, while the other half was used to test the performance of traditional furrows. Traditional furrow irrigation consists of a main earthen ditch that distributes water into the other nine furrow lines. Eleven monitoring posts (stations) were installed along each furrow, with a spacing of $5 \mathrm{~m}$ between each post, to record the irrigation advance and recession time. The layout and dimensions of the furrows are illustrated in (Figure 2). 

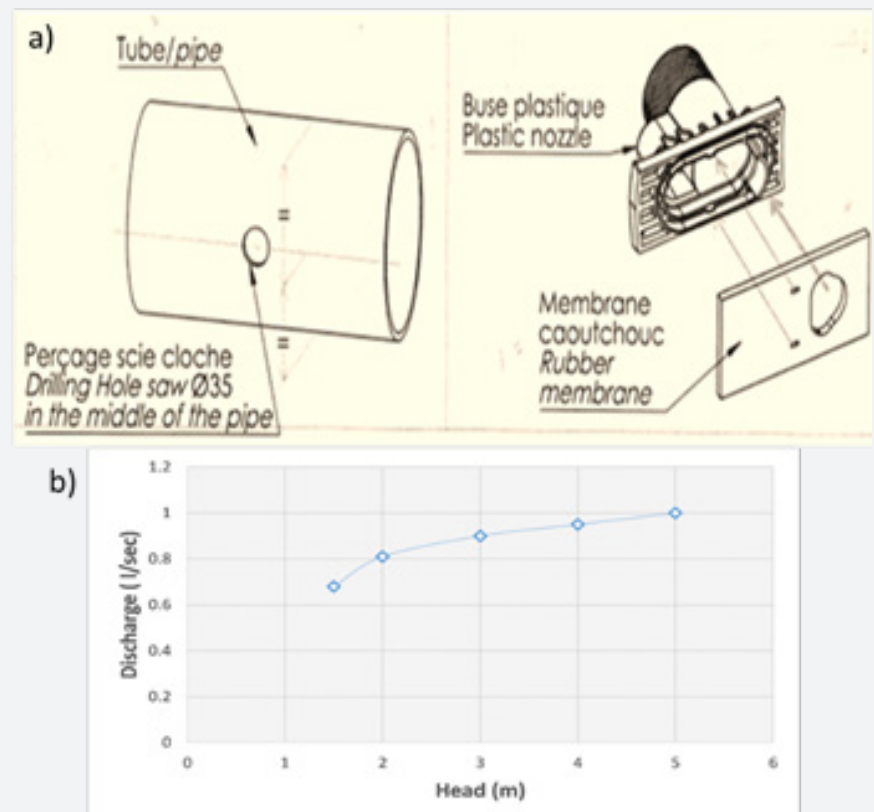

Figure 1a: Detailed design of the self-compensating outlets, and b) the rating curve for an outlet (source: ROLLAND, France).

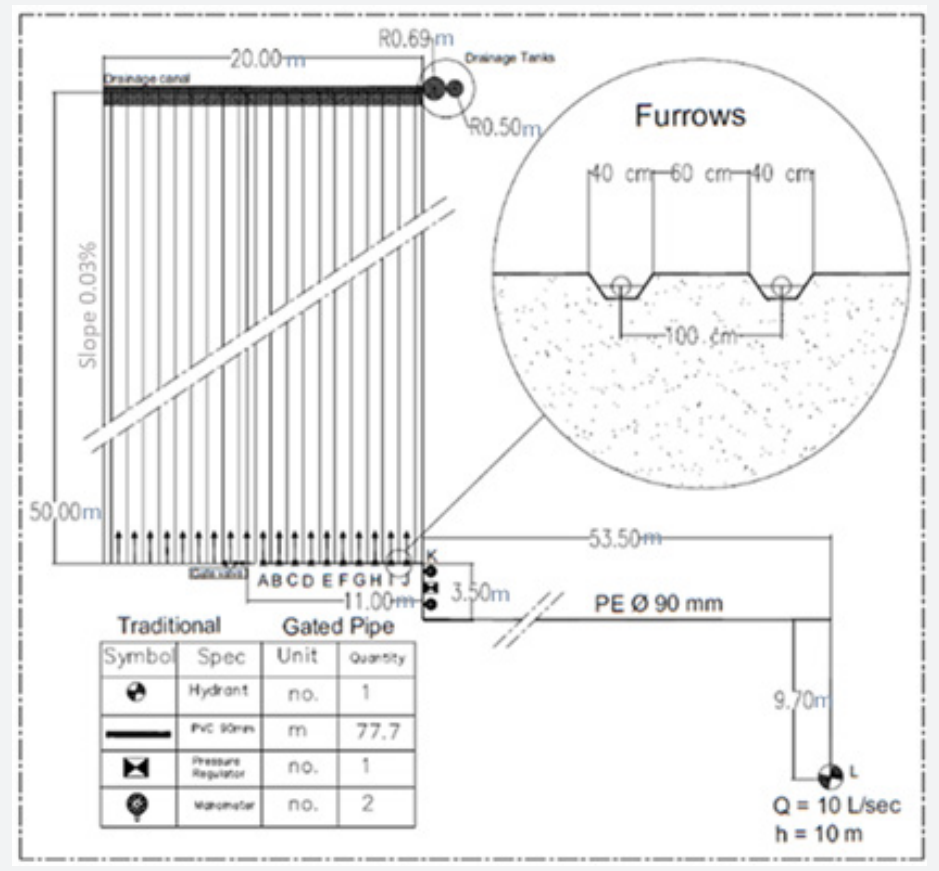

Figure 2: Layout of the experimental field.

Surface furrow irrigation is characterized with its concavities combined (usually) with small canals along the longitudinal slopes, ending with a runoff collective drain. For this study, a free-draining furrow was considered. In such case, depletion and recession phases are very short compared to the advance and filling phases. Thus, due to their significant impact on the overall performance of furrow irrigation events, the study focuses on the sensitivity of the last-mentioned two phases to the innovative technology and management practices. (Figure 3) shows the drainage canal at the end of the field. The irrigation runoff was collected via a channel into two calibrated tanks with a total volume of 2500 liters. A submersible pump was connected to the tanks to be used when 


\section{Civil Engineering Research Journal}

they are full. The gated pipe network consisted of Polyethylene pipe with a $90 \mathrm{~mm}$ diameter with hydraulic roughness $=0.007$ $\mathrm{mm}$ equivalent to $\mathrm{c}=150$ in Hazen Williams. The friction losses were calculated using Hazen Williams's equation. The pipes diameter was selected according to the maximum allowed flow velocity, $\mathrm{v}=1.5 \mathrm{~m} / \mathrm{s}$. The last outlet discharge was designed to provide $0.8 \mathrm{l} / \mathrm{sec}$. A pressure regulator was used to reduce and fix the pressure upstream of the gated pipe. Two manometers were installed to check the pressures upstream and downstream the flow regulator. A flow meter was installed to measure the water volume applied at each irrigation event.

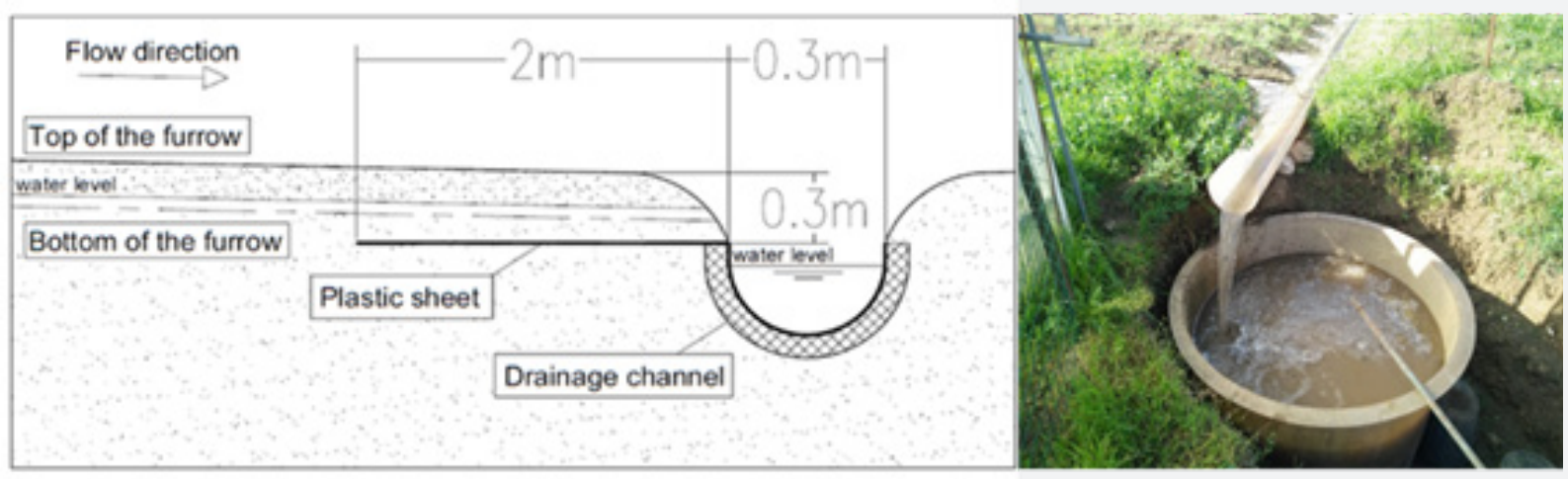

Figure 3: Cross sectional view for the drainage channel.

\section{Soil physical properties}

A mechanical-physical analysis was done prior to the experiment at two different interval depths $(0-10$ and $10-30 \mathrm{~cm})$ to identify the texture properties, soil physical data were averaged on 10 disturbed samples collected each $5 \mathrm{~m}$ along the $8^{\text {th }}$ furrow for both depths. In the same way, 10 more undistributed soil samples were collected to determine the initial soil water content by applying thermo-gravimetric method. While the available soil water content (ASW) was extrapolated from a soil hydraulic characterization done through monitoring with a tensioninfiltrometer [20]. All data are listed in (Table 1).

Table 1: Soil physical properties.

\begin{tabular}{|c|c|c|c|c|c|c|c|c|c|c|}
\hline \multirow{2}{*}{$\begin{array}{l}\text { Soil Depth } \\
\text { (cm) }\end{array}$} & \multirow{2}{*}{ FC (\%) } & \multirow{2}{*}{$\begin{array}{l}\text { WP } \\
\text { (\%) }\end{array}$} & \multirow{2}{*}{$\begin{array}{l}\text { ASW } \\
(\%)\end{array}$} & \multirow{2}{*}{$\rho_{\mathrm{b}}\left(\mathrm{gcm}^{-3}\right)$} & \multicolumn{3}{|c|}{$\begin{array}{c}\text { Particle size distribution } \\
(\%)\end{array}$} & \multirow{2}{*}{ Texture class } & \multirow{2}{*}{$\begin{array}{l}\text { Stone Mass } \\
\text { Percentage in } \\
\text { Soil (\%) }\end{array}$} & \multirow{2}{*}{$\begin{array}{c}\text { Initial Soil } \\
\text { Water Content } \\
\text { (\%) }\end{array}$} \\
\hline & & & & & Sand & Clay & Loam & & & \\
\hline $0-10$ & 14.9 & 5.6 & 9.3 & 1.11 & 46.3 & 14.5 & 39.2 & loam & 32 & 16.8 \\
\hline $10-30$ & 13.2 & 4.4 & 8.8 & 1.14 & 42.4 & 14.5 & 43.1 & loam & 20 & 20 \\
\hline
\end{tabular}

Where FC: Field Capacity; WP: Wilting Point; ASW: Available Soil Water Content; $\rho_{\mathrm{b}}$ : Bulk Density

\section{Measuring soil infiltration}

Soil infiltration is a complicated process that is a function of several factors, i.e. soil texture, soil structure, tillage operations, compaction, soil initial water content, air entrapment, soil salinity, water salinity and time, which is the most relevant. There are numerous on-site field methodologies used to measure soil infiltration rate, i.e. ring, double ring, blocked furrow, continuous flow, as well as several simulation approaches. For simplicity, in this study, soil infiltration curve was conducted on-site using a double ring infiltrometer [21]. Double ring infiltrometers are not the best option when modeling furrow irrigation as it is not taking horizontal infiltration into consideration and unlike furrows, water is stagnated during the test. However, for simplicity and for practical reasons, it was used to extract the empirical parameters for Kostiakov function, as it was used in several studies [22]. From the infiltration test, the relation between the infiltration rate and the accumulated infiltrated depth with time was plotted and the Kostiakov parameters were extracted as the regression on the curve (Figure 4).

Then Koskiatov-Lewis equation was used to generate the parameters of the empirical relation.

$$
i=k a \tau^{a-1}
$$

where $i$ is the infiltration rate in $\mathrm{mm} / \mathrm{hr}, \tau$ is the opportunity time (hr), $k$ and $a$ are empirical parameters. 


\section{Civil Engineering Research Journal}

The integration of the regression of the curve is representing the cumulative infiltrated depth:

$$
\begin{gathered}
Z=\int_{0}^{\tau} i(\tau) \mathrm{d}(\tau) \\
Z=k \tau^{a}+f_{0} \tau
\end{gathered}
$$

where $Z$ is the cumulative infiltrated depth (mm). For this location and from the empirical relation in (Figure 4):

$$
Z=39.31 \tau^{0.4435}+1.76 \tau
$$

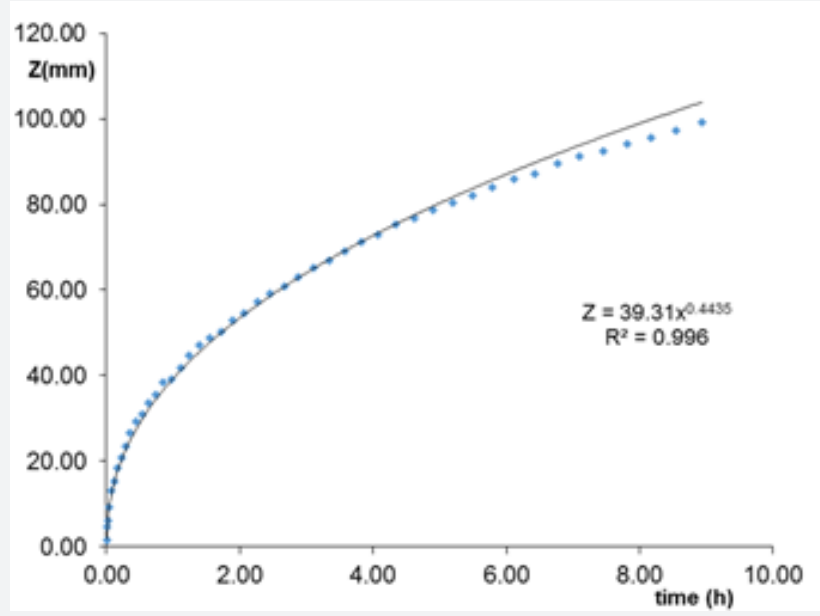

Figure 4: The cumulative infiltrated depth and Kostiakov parameters.

\section{WinSRFR and surface irrigation modelling}

For this study WinSrfr version 3.4.1 (download on www.ars. usda.gov) was used. WinSRFR is an integrated software package developed for hydraulic analysis of surface irrigation systems. Users can analyze the performance irrigation events and estimate field-average infiltration parameters based on field-measured data, formulate design and operational alternatives, and conduct simulation studies using an unsteady one dimensional flow model. The functionality and organization of WinSRFR were defined based on the analytical process typically followed in assessing and improving the hydraulic performance of surface irrigation systems. Program functionalities, referred to as WinSRFR Worlds, are Event Analysis, Operation Analysis, Physical Design, and Simulation.

In the present study the simulation function was used to design the irrigation event and to compare both systems within the optimal expected performance. It is worthy to mention that WinSRFR do not consider the water delay impact from the main ditch on the advance phase in the furrows, hence it considers one starting time for all the furrows and assumes identical repetitive furrow or set of furrows.

\section{Event simulations}

The application efficiency (AE) and distribution uniformity (DU) are the main indicators to evaluate the overall performance of any surface irrigation event. These indicators are dependent on a number of designing and operating factors, mainly:

a. Upstream discharge (Q) b. $\quad$ Field slope $(\mathrm{S})$

c. Field dimensions $\left(\mathrm{L}^{*} \mathrm{~W}\right)$

d. Soil infiltration rate $(i)$

e. Roughness (n)

f. Furrow cross-sectional dimensions $(\mathrm{V} / \mathrm{H})$

g. Duration of the event (time of cutoff) (Tc)

h. And targeted infiltrated depth (Zr)

As the objective of the study is to compare the two systems, except for Tc and $\mathrm{Zr}$, all of the above-mentioned factors are assumed to be constant along the field (no spatial variability was taken into consideration). The expert user tends to raise the performance of any irrigation event by selecting the best cutoff time for each irrigation event, and when possible the upstream discharge $\mathrm{Q}$. This time ensures the best combination of the possible minimum drainage with the maximum possible retained water in the targeted soil depth.

Assuming the inflexibility of all other factors is usually valid. However, many on-farm practices could impact the mentioned factors and could be used to enhance performance. For example, using gated pipe alternate irrigation, the odd (e.g. furrows number $1,3,5$...etc.) and even furrows (e.g. furrows number 2, 4, 6 ...etc.) are irrigated separately, doubles the available discharge per furrow. While surge irrigation exploits the crusting and consolidation phenomena to reduce the advance time. However, in the present study, such practices are not taken into consideration, as the main objective is comparing gated pipes to conventional 
furrow irrigation. The infiltration process was considered in one dimension only, in which the infiltration rate is a function of time and distance only. The pertinent infiltration is the volume infiltrated per unit length $A_{z}(x, t)\left[\mathrm{L}^{3} / \mathrm{L}\right]$ as in [23]:

$$
A_{z}=W P . z
$$

Where WP [L] is the transverse length of the soil-stream interface through which the infiltration takes place, and $\mathrm{v}$ is the volume infiltrated per unit length per unit width of the soil surface $\left[\mathrm{L}^{3} / \mathrm{L}^{2}\right]$. The wetting perimeter variation with time and its impact on infiltration was not taken into consideration as only the vertical infiltration rate was measured in Eq. (5). WinSRFR is representing $A_{z}$ as the product of furrow spacing and $z$. the resulted Kostiakov parameters are the parameters of $A_{z}$ divided by furrow spacing (except for the dimensionless parameter $a$ ). With these assumptions in mind, the event was simulated using WinSRFR [23]. All the simulation data were gathered from the field. The required infiltrated depth $(\mathrm{cm})$, which depends on the expected root zone depth, the deficit prior to irrigation, and the soil characteristics. As there are no crops cultivated, the required infiltrated depth was assumed to be $25 \mathrm{~mm}$. The next step is to figure out the cutoff time. Trial and error simulations were used. For each trial, the same data were inserted in the model and the cutoff time was changed by 10 min steps. Then the $\mathrm{AE}$ and DU were reviewed. The results showed that $30 \mathrm{~min}$ is expected to achieve $82 \%$ for $\mathrm{AE}$ and $83 \%$ for DU. Compared to 20 and 40 min for cutoff, this combination was the most appropriate. Lower irrigation time will achieve higher $\mathrm{AE}$ and lower $\mathrm{DU}$, while increasing the time to 40 min will decrease the $\mathrm{AE}$ and increase the DU.

\section{Field trials}

The simulated event was applied in the field using both systems. For all furrows, the advance and recession times and the amount of drainage were measured on the field. The event was analyzed using the advance recession curves and KoskiatovLewis to calculate the infiltrated depth at the eleven posts for each furrow, $5 \mathrm{~m}$ between each post (i.e. $8 * 11$ posts).

Finally, The DU was calculated according to the average infiltrated depth of the low quarter in the whole field (the lowest 22 points) relative to the total average infiltrated depth [24].

$$
D U=\frac{\text { Average infiltrated depeth in the end quarter }(\mathrm{cm})}{\text { Average infiltrated depeth }} * 100(7)
$$

Regarding the measurements of the $\mathrm{AE}$ in the field, the runoff was collected by the drainage channel into the calibrated reservoirs and measured after each event, while the amount of water applied was measured using the flowmeter. The drainage was considered the only irrigation water losses [25].

$$
A E=\frac{\left(V_{a p}-V_{r o}\right)}{V_{a p}} * 100(8)
$$

where $V_{a p}$ is the amount of water applied in $\mathrm{m}^{3}$ and $V_{r o}$ is the runoff in $\mathrm{m}^{3}$ (drainage).

It is important to clarify the relation between the cutoff time, AE and DU in surface irrigation comparative assessments. Assuming water availability, DU in the root zone is the main factor impacting the yield. Thus, low performance surface irrigation events usually mean longer cutoff time and lower AE rather than lower DU. Farmers intuitively tend to irrigate more and for a longer time to attain higher DU. Thus, using the same irrigation time as a benchmark for comparison is valid as long as the final results for both systems show satisfactory DU (above 80\%). The actual difference between the two surface irrigation systems relies on comparing AE for the same irrigation time and the resulting DU level, as farmers (users) would do.

Therefore, the comparison is done following three steps:

a. Starting the trials by the self-compensated gated pipe system and calculating $\mathrm{AE}$ and DU using 30 min cutoff time as generated from the model;

b. the second trial is done by testing the traditional furrow system for the same cutoff time (30 $\mathrm{min}$ ) and under the same conditions; and

c. in the same trial, the DU is evaluated. In case of insufficient DU, the event cutoff time is extended to achieve higher DU (above 80\%).

For the third step, to evaluate the DU in the field, the variation of the time of advance was used as an indicator for the satisfactory or non-satisfactory DU. Because infiltration is assumed to be uniform over the field, the variation in intake opportunity time (the deference between the advance and recession times at each point in the field) is an indication of the uniformity. However, in free ending furrow irrigation, the recession phase is very fast in the entire field compared to the advance. Thus, the time of advance is the main contributor to the DU. The quarter time rule is widely used to obtain satisfactory irrigation event. This means that the advance phase should finish in a quarter of the time needed to fill the root zone with the required depth that could be determined from the infiltration curve [26]. The average opportunity time to infiltrate the required depth at any point is calculated from Koskiatov fromula (see equation 5). If the required depth is $Z$ $=2.5 \mathrm{~cm}$, then the irrigation duration is $\tau=22-23 \mathrm{~min}$, and the advance phase should finish in around 7-8 min. In other words, the average allowed opportunity time in the low quarter should not get below $20 \mathrm{~min}$. Thus, the following rule was used to evaluate DU in the field. If the advance phase did not finish on time, the irrigation event is extended until the average opportunity time in the low quarter of the field is around $20 \mathrm{~min}$, or the discharge $Q$ shall be increased.

\section{Results}

\section{Irrigation events analysis}

Once the data were collected after the trials, the model was validated by comparing the simulated scenario and the measured parameters using the self-compensating gated pipe system 


\section{Civil Engineering Research Journal}

results. The recorded advance-recession times and Kostiakov parameters were inserted into the model to generate the actual advance and recession curves. (Figure 5) shows both actual and simulated curves of one of the furrows.

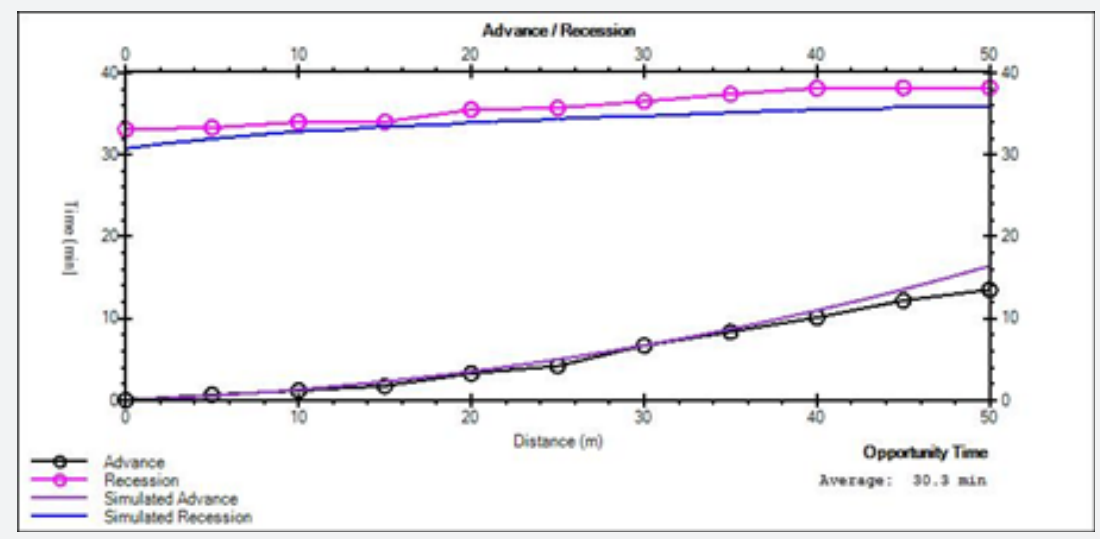

Figure 5: Actual and simulated advance and recession curves for furrow number 8 under gated pipe system.

\section{Performance of the system}

The AE was quite high for both systems considering initial soil water depletion. Using gated pipe systems, and by applying 11.46 $\mathrm{m}^{3}$ in $30 \mathrm{~min}$, the measured drainage in the reservoirs was $2.1 \mathrm{~m}^{3}$. This has resulted in an application efficiency of $82 \%$. By using the traditional surface irrigation system, for the same applied volume and duration, the amount of drainage was $2.5 \mathrm{~m}^{3}$. This has resulted in slightly lower efficiency of $78 \%$. However, AE cannot be used alone to evaluate a surface irrigation event. Some of the furrows under traditional surface irrigation failed to complete the advance phase in 30 min (no. 5, 6, 7 and 8), thus the irrigation event was extended by another $15 \mathrm{~min}$ to achieve a satisfactory DU. After 45 min, the AE decreased to $70.7 \%$ (out of $17.45 \mathrm{~m}^{3}$ of water applied, $5.1 \mathrm{~m}^{3}$ was measured as drainage), while the DU reached $79 \%$.

The significant difference between the two systems lays in shorter advance times (7-10 min) and steady uniform discharges achieved by the self-compensated gated pipe system, which resulted in a decrement in the variation of opportunity times between the furrows and raised the DU to almost $96 \%$ in 30 min with $82 \% \mathrm{AE}$. In traditional furrow system, the variation of the discharges among the furrows affected the advance phase. The advance was very fast in the first furrows and deteriorated gradually towards the last furrow, resulted in a longer irrigation event. It is important to notice how the drainage water increased from $2.5 \mathrm{~m}^{3}$ in the first $30 \mathrm{~min}$ to $5.1 \mathrm{~m}^{3}$ in $45 \mathrm{~min}$ (that is an increment of $50 \%$ of drainage water). As the advance phase is not uniform, and the infiltration rate decreases with time, the furrows that finish the advance early contributed more to tail water in the added $15 \mathrm{~min}$. The relation between the amount of drainage from each furrow and the infiltration rates is controlled by the difference between the advance and the cutoff time for each furrow. It is worth mentioning that DU in this type of surface irrigation is subjected to the skills of the irrigators and their ability to control the discharges of all the furrows during the irrigation event. (Figures 6a \& 6b) show the advance-recession curves of the first and the last two furrows of both systems, this highlights the adaptation of the innovative gate for large plots where the difference in pressure head may be important between the first and last gate.

\section{The events simulation and analysis}

The results revealed that WinSRFR is more valid for simulating gated pipe systems over traditional systems. It is also more accurate in simulating AE over DU mainly because of the software's assumption of one repetitive identical furrow. Thus, the simulator does not take the horizontal field spatial variability into account. The simulated AE was $79 \%$ while the simulated DU was $89 \%$ in 30 min cutoff time. The measured AE of the selfcompensated gated system was $82 \%$ while the DU was higher $96 \%$. The interpretation of these results lays in the simulation of the advance time. The model generated a simulated advance time of 16 min and assumed repetitive identical furrows. Thus, the DU of one furrow is representative for the DU of the entire field. In reality, the advance time using gated pipes was shorter in all furrows by $12-40 \%$ while the traditional furrows showed high variability in the advance behavior. In the first three furrows, the measured advance time was shorter than the simulated by $20-40 \%$, then it increased dramatically by $40,100,120$ and $150 \%$ towards the end.

\section{Conclusion}

With proper management, using modified gated pipe systems can significantly enhance surface irrigation performance in terms of $\mathrm{AE}$ and DU. These systems can even be comparable to pressurized systems. Furthermore, these systems consume less energy and require less maintenance. The modified gated pipes 


\section{Civil Engineering Research Journal}

raised the performance by $11 \%$ in terms of $\mathrm{AE}$ (reduction of drainage water), $20 \%$ in terms of DU and reduced the irrigation time by $30 \%$ compared to traditional systems. The proposed system could also be a better alternative in regions distinguished with seasonal water availability or rotational schedules (high fixed discharges in small, fixed durations), flat topography and traditional use of surface irrigation, where low irrigation performance can be mainly interpreted to mismanagement rather than water scarcity. In addition to the demonstrated improvement in DU and AE at the farm level, it is expected that the system will have

i) an environmental impact by reducing drained polluted water due to $\mathrm{AE}$ improvement, and

ii) a social impact by reducing the irrigation time, increase the number of events per week and consequently reduce rotational intervals. Such impacts had to be assessed with further research at the irrigation district level. WinSRFR proved to be more accurate in predicting self-compensating gated pipe systems compared to traditional surface irrigation systems. Finally, to increase the added value of the use of the model to define furrow irrigation management and the simulation of DU, the model should be improved to take a better account of the variability of furrows infiltration capacity over a field.
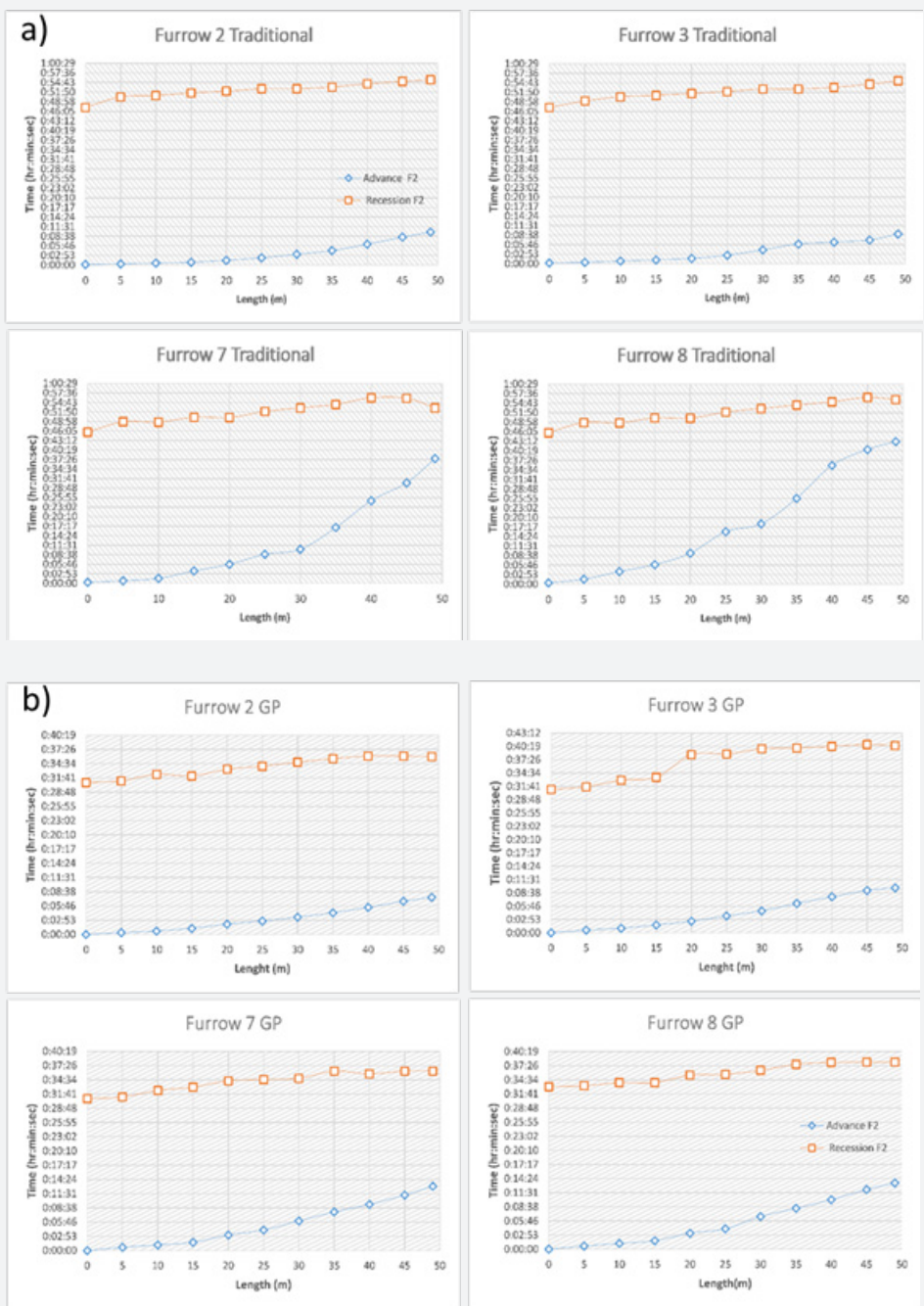

Figure 6: Advance-Recession curves of the first and last two furrows under a) traditional furrow irrigation, and b) self-compensated gated pipes.

\section{Funding}

This research was funded by the EU-MADFORWATER project, grant number H2020-E.3.5.4 GA ID: 688320.

\section{References}

1. (2014) FAO Area equipped for irrigation. Prepared by Aquastat, FAO’S global water information system. 


\section{Civil Engineering Research Journal}

2. Perry C, Steduto P (2017) Does improved irrigation technology save water? A review of the evidence. FAO: Cairo, Egypt.

3. Singh H, Mishra D, Nahar NM (2002) Energy use pattern in production agriculture of a typical village in arid zone, India-part I. Energy Conversion and Management 43(16): 2275-2286.

4. Tarjuelo JM, Rodriguez-Diaz JA, Abadía R, Camacho E, Rocamora C, et al. (2015) Efficient water and energy use in irrigation modernization: Lessons from Spanish case studies. Agricultural Water Management 162: 67-77.

5. Walker WR, Skogerboe GV (1987) Surface Irrigation: Theory and Practice; Prentice-Hall.

6. Smith RJ, Watts PJ, Mulder SJ (1986) Analysis and design of gated irrigation pipelines. Agricultural Water Management 12: 99-115.

7. Osman HE (2000) Gated pipes techniques for improved surface irrigation. Annals of Agricultural Science (Cairo) 1: 145-155.

8. Constable GA, Hodgson AS (1990) A comparison of drip and furrow irrigated cotton on a cracking clay soil. Irrigation Science 11: 149-153.

9. Hansona BR, Schwankl LJ, Schulbach KF, Pettygrove GS (1997) A comparison of furrow, surface drip, and subsurface drip irrigation on lettuce yield and applied water. Agricultural Water Management 33 139-157.

10. Ali OAM, Mohammed ASH (2015) Performance Evaluation of Gated Pipes Technique for Improving Surface Irrigation Efficiency in Maize Hybrids. Agricultural Sciences 6(5): 21.

11. Osman HE (2002) Evaluation of surface irrigation using gated pipes techniques in field crops and old horticultural farm. Annals of Agricultural Science (Cairo) 461-476.

12. Osman R, Ferrari E, McDonald S (2016) Water Scarcity and Irrigation Efficiency in Egypt. Water Economics and Policy 02: 1650009.

13. Abdel-Raheem HA, Elwan AM (2016) Gated Pipes Irrigation System for Optimum Water Productivity of Sugar cane in Egypt 12(7): 215-225.

14. Kang SZ, Shi P, Pan YH, Liang ZS, Hu XT, et al. (2000) Soil water distribution, uniformity and water-use efficiency under alternate furrow irrigation in arid areas. Irrigation Science 19: 181-190.

15. El-Hagarey M (2015) Innovative Automatic Self-Compensating Gated Irrigation Pipes; LAP LAMBERT Academic Publishing.
16. Awady ME, Tantawy MTE, Hassan SS, Ashhab AOME (2003) WaterFlow uniformity through irrigation gated-pipes. In: Proceedings of International Workshop on Improved Irrigation Technologies and Methods: Research, Development and Testing, p. 18-19.

17. El-Shafie A, Beder O, Hussein M, El-Gindy A (2009) Performance analysis of self-compensating gated pipe for improving surface irrigation efficiency. Misr J Agric Eng 26: 1318-1335.

18. El-Shafie AF, Osama MA, Hussein MM, El-Gindy AM, Ragab R (2017) Predicting soil moisture distribution, dry matter, water productivity and potato yield under a modified gated pipe irrigation system: SALTMED model application using field experimental data. Agricultural Water Management 184: 221-233.

19. Rodríguez-Díaz, JA, Pérez-Urrestarazu L, Camacho-Poyato E Montesinos P (2011) The paradox of irrigation scheme modernization: more efficient water use linked to higher energy demand. Spanish Journal of Agricultural Research 9: 1000-1008.

20. Ankeny MD, Ahmed M, Kaspar TC, Horton R (1991) Simple Field Method for Determining Unsaturated Hydraulic Conductivity. Soil Science Society of America Journal 55: 467-470.

21.(2009) ASTM-D3385-09 Standard Test Method for Infiltration Rate of Soils in Field Using Double-Ring Infiltrometer. ASTM International: West Conshohocken, PA, USA.

22. Waller P, Yitayew M (2016) Irrigation and Drainage Engineering; Springer International Publishing.

23. Bautista E, Schlegel JL, Strelkoff TS (2012) WinSRFR 4.1 User Manual; USDA-ARS U.S. Arid Land Agricultural Research Center: Maricopa, AZ USA, pp. 1-175.

24. Clemmens AJ, Solomon KH (1997) Estimation of Global Irrigation Distribution Uniformity. Journal of Irrigation and Drainage Engineering 123: 454-461.

25. Howell T (2003) Irrigation efficiency In Encyclopedia of Water Science. In: Stewart BA, Howell TA, Eds. Marcel Dekker: New York, USA, p 1-6.

26. Walker WR (1989) Guidelines for Designing and Evaluating Surface Irrigation Systems Food and Agriculture Organization of the United Nations.

Your next submission with Juniper Publishers
will reach you the below assets
- Quality Editorial service
- Swift Peer Review
- Reprints availability
- E-prints Service
- Manuscript Podcast for convenient understanding
- Global attainment for your research
- Manuscript accessibility in different formats
( Pdf, E-pub, Full Text, Audio)
- Unceasing customer service
Track the below URL for one-step submission
https://juniperpublishers.com/online-submission.php

